\title{
Diversidade cultural: desafios para o desenvolvimento de lideranças globais
}

\author{
Fernando Zeni Alvarenga ${ }^{1}$ \\ Raquel Prá ${ }^{2}$ \\ Jhony Pereira Moraes ${ }^{3}$ \\ Maurício Gregianin Testa ${ }^{4}$
}

\begin{abstract}
Resumo: As mudanças advindas da internacionalização das organizações trouxeram diversos desafios para as áreas de recursos humanos, como a dispersão geográfica das equipes e a necessidade de desenvolver líderes globais. Com base nesse contexto, o objetivo do presente estudo de caso é identificar diferenças culturais entre membros de quatro nacionalidades distintas (americana, brasileira, indiana e malaia) que compõem uma equipe distribuída globalmente de uma empresa de TI. O instrumento utilizado para a análise engloba o modelo de quatro dimensões proposto por Hofested (2001). Por meio desse levantamento, buscou-se demonstrar os desafios vivenciados por líderes globais para gerir a diversidade cultural, mantendo a efetividade organizacional e a importância de inclusão deste tema pela área de recursos humanos nos programas de desenvolvimento de lideranças globais. Foi possível concluir, através do estudo, que competências como mente aberta, sensibilidade global, empatia, aceitação da complexidade e suas contradições, comunicação intercultural e abertura são essenciais para atuar nesse contexto.
\end{abstract}

Palavras-chave: Liderança global; Diversidade cultural; Internacionalização.

\section{Cultural diversity: challenges for the development of global leaderships}

\begin{abstract}
The changes brought about by the internationalization of organizations have brought diverse challenges to the human resources areas, such as geographic dispersion of teams and the need to develop global leaders. Based on this context, the purpose of this case study is to identify cultural differences between individuals of different nationalities (Americans, Brazilians, Indians and Malaysians) who are part of a globally distributed IT company. The instrument used for the analysis encompasses the fourdimensional model proposed by Hofested (2001). The aim of this research was to demonstrate the challenges faced by global leaders in managing cultural diversity while maintaining organizational effectiveness and the importance of including this theme in the area of human resources in global leadership development programs. It was possible to conclude from the study that competences such as open mind, global sensitivity, empathy, acceptance of complexity and its contradictions, intercultural communication and openness are essential to act in this context.
\end{abstract}

Keywords: Global leadership. Cultural diversity. Internationalization.

\footnotetext{
${ }^{1}$ Bacharel em Administração, pela Pontifícia Universidade Católica do Rio Grande do Sul (PUCRS).

${ }^{2}$ Mestranda em Administração na Universidade Federal do Rio Grande do Sul (UFRGS) desde 2017/1. Especialista em Psicologia Organizacional pela UFRGS. Graduada em Psicologia pela Pontifícia Universidade Católica do Rio Grande do Sul (PUCRS).

${ }^{3}$ Mestrando em Administração (área de Gestão de Pessoas e Relações de Trabalho) pelo Programa de PósGraduação em Administração da Universidade Federal do Rio Grande do Sul (PPGA/UFRGS)

4 Doutorado em Administração pela Universidade Federal do Rio Grande do Sul (UFRGS). Professor Adjunto da Pontifícia Universidade Católica do Rio Grande do Sul (PUCRS)
} 


\title{
Diversidad cultural: desafíos para el desarrollo de liderazgo global
}

\begin{abstract}
Resumen: Los cambios surgidos de la internacionalización de las organizaciones trajeron diversos desafíos para las áreas de recursos humanos, como la dispersión geográfica de los equipos y la necesidad de desarrollar líderes globales. Con base en ese contexto, el objetivo del presente estudio de caso es identificar diferencias culturales entre los miembros de cuatro nacionalidades distintas (americana, brasileña, india y malasia) que constituyen un equipo distribuido globalmente de una empresa de TI. El instrumento utilizado para el análisis engloba el modelo de cuatro dimensiones propuesto por Hofested (2001). Por medio de una encuesta, se buscó demostrar los desafíos vivenciados por líderes globales para gestionar la diversidad cultural, manteniendo la efectividad organizacional y la importancia de inclusión de este tema por el área de recursos humanos en los programas de desarrollo de liderazgos globales. Se pudo concluir, a través del estudio, qué competencias como mente abierta, sensibilidad global, empatía, aceptación de la complejidad y sus contradicciones, comunicación intercultural y apertura son esenciales para actuar en el contexto.

Palabras clave: Liderazgo global; Diversidad cultural; Internacionalización.
\end{abstract}

\section{Introdução}

A internacionalização das empresas e o aumento do numero de operações no exterior com o objetivo de ampliar a possibilidade de uma organização competir no mercado global têm trazido grandes desafios para as empresas, dentre eles, gerenciar a diversidade nas organizações (COX, 1994). Nesse contexto, surge a figura do líder global, responsável por gerenciar equipes de indivíduos, com diferentes contextos culturais e que podem estar dispersos em diferentes lugares do mundo (MENDENHALL, 2013).

Os estudos sobre liderança global ainda são emergentes, pois, apesar do crescente interesse pelo tema, a partir da década de 90, ainda são minoria dentre os estudos sobre negócios internacionais (MENDENHALL, 2013). Os estudos sobre expatriação permitiram uma maior familiaridade com o tema, embora um líder global não seja necessariamente um expatriado (JOKINEN, 2005), isto é, ele pode gerir uma equipe global, mas não precisa ter realizado uma movimentação para outra região.

Diversas competências englobando conhecimentos, habilidades e características pessoais são elencadas pela literatura como necessárias para um líder global (AMAGOH, 2009; CALIGIURI, 2006; CALIGIURI E TARIQUE, 2008; HASSANZADE, SILONG, ASMUNI e WAHAT, 2015; JOKINEN, 2005; MENDENHALL, 2013). Dentre elas, adquire significativa relevância a competência intercultural que constitui a capacidade do líder para lidar com indivíduos de diferentes culturas de forma empática e compressiva, conseguindo obter o melhor desempenho deles em situações diversas (MENDENHALL, 2013). 
A convivência com a diversidade cultural - de gênero, raça, nacionalidade e outras -, além de uma imposição diante das mudanças ocorridas no mercado de trabalho, mostrase um dos grandes desafios para a gestão das organizações. Seu valor estratégico reside na influência sobre os comportamentos organizacionais e no impacto causado nos resultados organizacionais (COX, 1994).

Cientes da necessidade de desenvolver líderes globais preparados para lidar com a diversidade cultural, as empresas têm adotado estratégias como a expatriação de executivos e programas de desenvolvimentos de lideranças, que podem envolver ou não a expatriação como metodologia (AMAGOH, 2009; CALIGIURI, 2006; CALIGIURI E TARIQUE, 2008; HASSANZADE, SILONG, ASMUNI e WAHAT, 2015; JOKINEN, 2005; MENDENHALL, 2013).Independente da metodologia adotada, é reconhecida a necessidade de uma avaliação prévia da compatibilidade do perfil profissional do colaborador com a complexa tarefa da liderança global(AMAGOH, 2009; CALIGIURI, 2006; CALIGIURI E TARIQUE, 2008).

Considerando-se como um item fundamental no programa de desenvolvimento de lideranças globais o treinamento intercultural (CALIGIURI, 2006), o propósito do presente estudo foi identificar diferenças culturais entre membros de quatro nacionalidades distintas (americana, brasileira, indiana e malaia) que compõem uma equipe distribuída globalmente de uma empresa de TI. Eles atuam em uma empresa multinacional de Tecnologia da Informação e trabalham diretamente em seus países de origem.

Para tanto, foram realizadas entrevistas semiestruturadas com uma amostra de 38 indivíduos, selecionada por conveniência (GIL, 2010), caracterizando-se um estudo de caso (YIN, 2010). Os dados foram categorizados de acordo com as quatro dimensões culturais propostas por Hofested - distância do poder, aversão à incerteza, individualismo versus coletivismo e masculinidade versus feminilidade - e analisados conforme o método de análise de conteúdo proposto por Bardin (2011).

O levantamento realizado permitiu identificar semelhanças e diferenças culturais entre as quatro diferentes nacionalidades. A compreensão das diferenças entre grupos culturais e a adequada gestão delas, alerta Cox (1994), permite transformar as práticas organizacionais com o intuito de maximizar potencialidades e minimizar aspectos negativos. Em função disso, objetivou-se, a partir dos dados encontrados, promover insights para o planejamento de programas de desenvolvimento de lideranças e informações para líderes globais gerenciarem as equipes sob a sua responsabilidade. 
O artigo está dividido em sete sessões a contar desta introdução. Segue-se a esta o referencial teórico, englobando os conceito de liderança global e gestão da diversidade e as quatro dimensões culturais proposta por Hofested (2001), a metodologia, a análise e a discussão dos resultados, as considerações finais e as referências.

\section{Fundamentação Teórica}

\subsection{Quando houver outro assunto abordado dentro da fundamentação teórica}

A globalização ocasionou diversas mudanças no mundo do trabalho. O trabalho padronizado fabril com atribuições que cabiam dentro de uma descrição de cargos estática foi substituído pela imprevisibilidade das situações de trabalho. O profissional que antes era especializado em apenas uma única atividade teve de tornar-se flexível e capaz de mobilizar as suas competências conforme as exigências específicas de cada situação com a qual se depara. As pessoas passaram a serem mais valorizadas e necessárias para, por meio de suas competências individuais, garantir o atendimento dos objetivos organizacionais (DUTRA, 2004; RUAS, 2005; ZARIFIAN, 2001).

No final dos anos 70, observou-se a expansão das operações empresariais em nível global e a consequente movimentação de recursos humanos ao redor do mundo. Desde essa época, a gestão de recursos humanos internacional denota profundo interesse de estudo no meio acadêmico (BLACK; MENDENHALL; ODDOU, 1991).

A internacionalização das organizações trouxe consigo a necessidade de compreender-se a complexidade do cenário global, com o intuito de garantir a competitividade (SCULLION, 1994; LINEHAN, SCULLION, 2002; STEVENS; ODDOU; FURUYA; BIRD; MENDENHALL, 2006). A Gestão de Recursos Humanos Internacional, nesse contexto, tem como atribuição o tratamento dos processos de atração, desenvolvimento e retenção de pessoas em multinacionais (AGUZZOLI; LENGER; MANFREDINI, 2007).

Assim como mudanças ocorrem em relação ao trabalho, os comportamentos esperados dos líderes estariam ao longo do tempo - e conforme a cultura - o que torna possível encontrar na literatura diversas teorias e pressupostos a definir o conceito de liderança (BASS; BASS, 2008). Dentre esses conceitos, especialmente a partir da década de 90, encontra-se o de líder global. Como o seu próprio nome sugere, originou-se a partir 
do estabelecimento de negócios globais e do desafio de gerenciar empresas e pessoas que estão dispersas em diferentes localidades geográficas (MENDENHALL, 2013).

Caligiuri e Tarique (2009) definem os líderes globais como profissionais que lidam com atividades relacionadas à integração e gestão em nível global. Jokinen (2005) explica que esses líderes podem ou não ser expatriados e os expatriados, da mesma forma, podem ou não ser líderes globais, ou seja, é possível gerenciar-se uma equipe de indivíduos localizados em diferentes países a partir de uma região fixa. Hassanzadeh, Silong, Asmuni e Wahat (2015) definem o líder global como aquele capaz de gerenciar a diversidade e a complexidade.

A compreensão teórica acerca das competências necessárias para lideranças globais parte de duas perspectivas: a visão de que é necessário desenvolver competências diferentes da liderança doméstica ou, então, de que as mesmas competências são necessárias, porém em um nível global (JOKINEN, 2005). Mendenhall (2013) aponta que, em relação aos líderes domésticos, os globais necessitam lidar com um ambiente mais complexo e dinâmico envolvendo pessoas com diferentes bagagens culturais.

Hassanzadeh, Silong, Asmuni e Wahat (2015) dividem em três níveis as competências esperadas dos líderes globais. Como características pessoais citam mente aberta, idealismo, adaptabilidade, destemor; como habilidades, experiência adquirida ao longo da vida e trabalho, sensibilidade e pensamento crítico global, e trabalho em equipe; como conhecimentos, aludem para a consciência acerca de problemas e culturas, multiculturalidade, autoconhecimento e noções de tecnologia da informação.

$\mathrm{Na}$ tentativa de estabelecer um modelo integrativo sobre as competências de lideres globais a partir da literatura pré-existente, Jokinen (2005) resume-as em três níveis. Competências essenciais como autoconhecimento, engajamento na transformação individual e curiosidade. Características mentais desejáveis como otimismo, autorregulação, habilidade para realizar julgamento social, empatia, motivação para atuar em um ambiente internacional, habilidades cognitivas, aceitação da complexidade e suas contradições, assim como comportamentos como habilidades sociais, habilidade para estabelecer redes de relacionamento, conhecimento e experiência.

Cox (1994) apresenta como o maior desafio dos líderes, na atualidade, a capacidade de lidar com a diversidade cultural. Para definir o conceito de diversidade cultural, a autora parte da conceituação de grupo cultural como um coletivo que se diferencia de outros compartilhando normas, valores ou tradições. A diversidade cultural é entendida como 
representantes de um sistema social que diferem em relação a sua afiliação a diferentes grupos e à significação que conferem à cultura. Embora reconhecida a importância de gerir a diversidade, Fleury (2000) verifica que grande parte das empresas brasileira só desenvolve programas de gestão da diversidade por imposição de suas matrizes.

Para demonstrar o impacto da gestão da diversidade nos resultados organizacionais, Cox (1994) apresenta um modelo que divide os impactos em relação ao clima de diversidade, resultados de carreira individual e efetividade organizacional. A autora explica que uma gestão satisfatória promove identificação individual, integração organizacional, previne conflitos entre grupos, interfere nos aspectos de satisfação relacionados ao trabalho e na performance dos colaboradores, além de refletir-se nos resultados organizacionais por meio de inovação, resolução de problemas, turnover e produtividade - em um nível primário -, e na lucratividade - em um nível secundário.

Apesar da diversidade de competências elencadas pela literatura como necessárias para os líderes atuarem em nível global de forma efetiva, o planejamento das ações de desenvolvimento promovidas pela área de recursos humanos, deve ter congruência com a estratégia organizacional como uma totalidade (JOKINEN, 2005). A escolha dos participantes também é de suma importância, pois não são todos os indivíduos que possuem as competências individuais necessárias para exercer a liderança global e, em função disso, obter os benefícios desse tipo de atividade (AMAGOH, 2009; CALIGIURI, 2006; CALIGIURI E TARIQUE, 2008).

Caligiuri (2006) afirma que os participantes dos programas de treinamento de lideranças globais devem possuir conhecimentos de cultura geral e negócios internacionais; habilidades de interação intercultural, língua estrangeira e também cognitiva; e características de personalidade como extroversão, concordância, consciência, estabilidade emocional e abertura. Jokinen (2005) acrescenta que a motivação em atuar globalmente é um fator essencial para que o aprendizado concretize-se.

Leskiw e Singh (2007) assinala que as melhores práticas em desenvolvimento de lideranças envolvem tanto a aprendizagem formal quanto a ativa, permitindo que os treinados experimentem as suas novas habilidades na prática e aprimorem-nas. Caligiuri (2006) realiza uma síntese das estratégias empregadas pelas empresas classificando-as em três tipos: aprendizagem didática (treinamento intercultural, de diversidade e de línguas), experienciais individuais (coaching, mentoring e programas de imersão em diferentes culturas) e experiência cultural intensiva em diferentes culturas. 


\subsection{A Cultura e as dimensões culturais de Hofested}

Conforme já referenciado, a possibilidade de compreender e lidar com a diversidade cultural reflete a complexidade das relações de trabalho, nas quais estão envolvidos os líderes na atualidade (COX, 1994, MENDENHALL, 2013). Em função disso, constata-se que práticas como treinamento intercultural devem ser incluídas nos programas de desenvolvimento de lideranças (CALIGIURI, 2006; CALIGIURI E TARIQUE, 2008), mas, para isso, é necessário compreender as diferenças e as semelhanças envolvidas entre indivíduos de diferentes culturas.

Assim sendo, com o objetivo de entender os motivos pelos quais as diferenças culturais refletem-se na complexidade das relações de trabalho atualmente, é essencial o entendimento e a compreensão do conceito de cultura, uma abstração, conforme Schein (2009). Neste sentido, a cultura possui algumas características, como: profundidade, estabilidade estrutural, padronização e extensão. Essas são particularidades básicas relacionadas com as crenças, valores, normas e regras compartilhadas por um mesmo grupo de indivíduos e determinarão a atuação deles tanto em situações internas, entre os seus assemelhados, como em circunstâncias externas, interações com indivíduos de culturas distintas.

Isto posto, o desenvolvimento da cultura dá-se em três níveis: suposições básicas, crenças e valores expostos e artefatos. O terceiro e menos perceptível por membros de outras culturas, as suposições básicas, está relacionado às reflexões verdadeiras e que não são negociáveis por parte dos membros do mesmo grupo em diversas situações do cotidiano como, por exemplo, o certo e o errado, as relações humanas e o próprio comportamento humano (SCHEIN, 2009).

O segundo nível, valores, corresponde às manifestações culturais, as quais estão diretamente fundamentadas e associadas com as crenças fundamentais e são indispensáveis para os indivíduos os quais compartilham princípios similares. No entanto, no contexto organizacional, os valores estarão atrelados para o comportamento apropriado dos trabalhadores, ou seja, conectados com os valores defendidos pela companhia (SCHEIN, 2009).

Finalizando, o primeiro nível, artefatos, é considerado, devido a sua tangibilidade, o mais fácil de ser observado por aqueles que não fazem parte de um determinado grupo, 
pois é perceptível ao olhar de qualquer pessoa através, por exemplo, da arte, arquitetura, tecnologia, ciência e outros. Entretanto, apesar da facilidade inicial descrita, esse nível é de difícil entendimento para aqueles que não fazem parte do grupo cultural em questão, pois eles não compartilham os mesmos valores e suposições básicas e, portanto, a compreensão é nula, equivocada e dispensável na maioria dos casos (SCHEIN, 2009).

Uma forma de diferenciar culturas em nível nacional é proposta por Hofested (2001) a partir de uma pesquisa realizada com colaboradores da empresa IBM, entre os anos de 1967 e 1973, com o objetivo de compreender atitudes de colaboradores, membros de diferentes culturas. A partir do estudo, o autor identificou quatro dimensões para a compreensão das diferentes culturas nacionais:

a) Distância do poder: diz respeito às distâncias hierárquicas e formas de distribuição do poder.

b) Aversão à incerteza: refere-se ao grau de tolerância a situações de ambiguidade e incerteza

c) Individualismo versus coletivismo: avalia o quanto as pessoas são autocentradas, preocupadas com seus próprios interesses ou, por outro lado, são voltadas para os coletivos, grupos, sociedade.

d) Masculinidade versus feminilidade: a masculinidade está relacionada à agressividade e competição, enquanto a feminilidade está ligada à cooperação e qualidade de vida.

Uma quinta dimensão foi acrescentada por Hofested (2001), após o estudo, tendo como base o modelo de Michael Harris Bond, para estudar culturas asiáticas. Trata-se da dimensão Orientação de curto prazo versus longo prazo que reflete o quanto uma sociedade mostra-se aberta ou não a modificar as suas tradições.

\section{Método}

O método escolhido para o presente trabalho foi o de estudo de caso, por permitir o estabelecimento de uma visão holística e uma análise mais profunda do fenômeno pesquisado (YIN, 2010). A coleta de dados ocorreu entre os meses de abril e agosto de 2014, através de entrevistas semiestruturadas com uma amostra selecionada por conveniência (GIL, 2010) de 38 colaboradores de uma empresa multinacional do ramo de Tecnologia da Informação pertencentes a quatro nacionalidades distintas. 
Dentre os participantes: 10 são americanos, 10 brasileiros, 11 indianos e sete malaios; 26 são homens e 12 mulheres; a média das idades é 37 anos; os cargos variam entre desenvolvedores, testadores, analistas de negócios e gerentes; o tempo médio de empresa é de oito anos. O roteiro utilizado baseia-se no desenvolvido por Donato (2013), o qual foi adaptado por Alvarenga (2015). Buscou-se, através do relato dos entrevistados, identificar características de suas culturas nacionais, de acordo com a sua própria visão e de seus pares.

Os dados foram analisados com base na metodologia de análise de conteúdo proposta por Bardin (2011), a qual compreende três etapas: a pré-análise, envolveu a primeira aproximação com os dados por meio da transcrição das entrevistas gravadas; a codificação, realizada conforme quatro das dimensões propostas por Hofested (2001), utilizando-se o software NVivo®;e a análise dos dados propriamente dita, conforme o referencial teórico dos estudo. A quinta dimensão proposta por Hofested (2001) não foi utilizada em função de ser direcionada para culturas asiáticas.

\section{Resultados e Discussão}

A opção da distribuição de equipes pela empresa pesquisada relaciona-se a questões de custos e qualificação de mão de obra, ou seja, é uma escolha estratégica. No entanto, não se perceberam através dos relatos dos entrevistados, que tenha sido realizada uma preparação prévia tanto por parte dos que exercem cargos de gestão quanto aos demais em relação à gestão da diversidade. Isso confirma o exposto por Fleury (2000) de que as empresas não têm se engajado de forma significativa para a elaboração e estratégias de gestão da diversidade.

\subsection{Dimensão 1: Distância do poder (Power Distance Index - PDI)}

Nas culturas indiana e malaia, percebe-se um índice maior de distanciamento do poder, o qual, segundo Hofested (2001), caracteriza culturas mais verticalizadas, com hierarquização e centralização do poder. Esse índice fica evidente na fala de um dos indianos: "Numa perspectiva gerencial, os gerentes têm muito poder, especialmente, em empresas indianas e eles vão realmente exercer esse poder.”. Corroborando com a ideia anterior, um dos malaios disse: “[...] Quem vai dizer o que é importante? Aquele que 
alegar 'eu sou seu diretor/gerente'. Então, há impacto da hierarquia nesse contexto [...]. Ele lhe pede para extrair um relatório e por razões hierárquicas dentro da organização você irá querer agradá-lo [...]".

Já, os americanos apresentam um índice baixo de distância do poder, sugerindo uma menor hierarquização das relações e relações mais igualitárias entre líder e subordinado, o que pode ser ilustrado pela fala de um dos americanos que comenta "Eu posso agir de forma independente ou fazer recomendações e eu não tenho que esperar por aprovações ou movimentos dos meus superiores".

Por outro lado, os brasileiros não ficaram situados em nenhum dos polos de maior ou menor distanciamento do poder. Isso pode ser um indício de que esse distanciamento é relativo e variável como relatado por um dos brasileiros entrevistados: "O meu nível de controle é alto, mas depende da pessoa com quem eu estou trabalhando. [...] eu tenho a necessidade de saber das coisas. Eu não consigo saber de tudo o tempo inteiro, pois é humanamente impossível, mas eu gosto de estar bem informado para a minha tomada de decisão [...]."

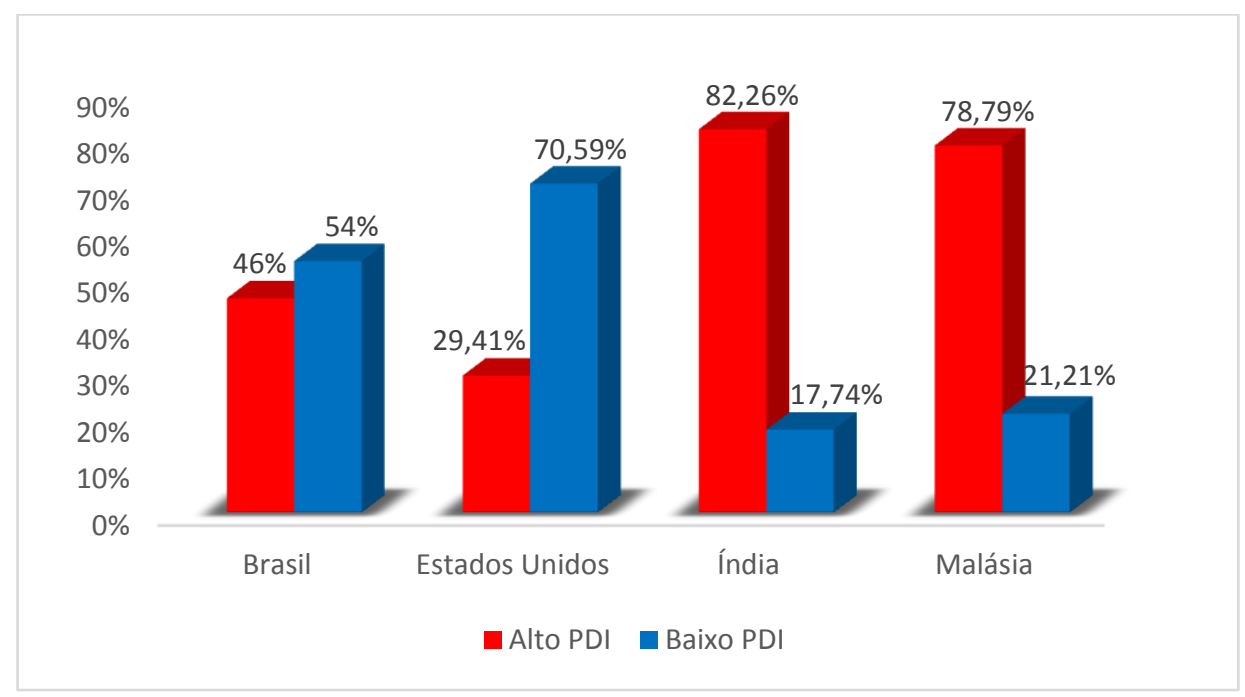

Figura 1: Resultados da dimensão distância do poder Fonte: Dados da pesquisa (2017)

Conforme a Figura 1 (um), os países (representados pelos trabalhadores) com alto distanciamento do poder (Power Distance Index - PDI) foram, em ordem, Índia e Malásia, sendo, respectivamente, 82,26\% e 78,79\%. Por outro lado, Brasil e Estados Unidos foram considerados os países com baixo PDI, como, na ordem, que segue: 54\% e 70,59\%. 


\subsection{Dimensão 2: Aversão à incerteza (Uncertainty Avoidance Index - UAI)}

As culturas brasileiras, americanas e malaias apresentam um índice mais elevado de aversão à incerteza em relação aos indianos. Segundo Hofested (2001), quanto mais alto ese índice é, maior será o grau de ameaça sentido pelos indivíduos frente à situação de incerteza e ambiguidades e, dessa forma, eles buscam certificar-se do domínio do maior número de informações possíveis antes de realizar uma determinada atividade. Essa preocupação fica evidente na fala de um dos brasileiros: "[...] os times no Brasil, quando eles têm alguma incerteza, eu vejo que eles criticam, questionam, procuram entender ou endereçar aquela incerteza antes de tomar alguma decisão [...]."

Já em relação aos americanos, também considerados com alto índice de aversão à incerteza, um dos indianos relatou: "Nos Estados Unidos, pela minha experiência, algum ponto de ambiguidade vai ser tratado detalhadamente para ser mitigado antes que ações maiores sejam realizadas." No mesmo sentido, porém em relação aos malaios, um dos brasileiros disse: "Na Malásia se não tiver escrito no papel e, em consequência disso, existir a possibilidade de gerar alguma incerteza, eles não vão para frente. Eles vão travar. Isso em processo de desenvolvimento ou mesmo de teste."

Por outro lado, os indianos sugerem uma maior tolerância às situações de incerteza e ambiguidade, evidenciada pelo índice encontrado. A fala de um dos indianos ilustra esta característica:

[...] Então, se há ambiguidade no início de um projeto, nós iremos colocar na cabeça que devemos fazer algo ao invés de ficar refletindo 'existe ambiguidade nisso ou naquilo' e ficar esperando alguém chegar com uma grande estratégia definida. Nós iremos começar colocando nossa cabeça no trabalho e trabalhar a partir disso. Isso pode resultar em uma falha e pode não dar certo, mas é assim que nós agimos. Aqui na Índia, nós vamos focar no trabalho mesmo que isso adicione riscos ao projeto em questão, pois você até pode acabar trabalhando em algo que não era exatamente o resultado almejado, mas nós iremos colocar a mão na massa ao invés de pensar sobre aquilo. E se algo for planejado novamente, nós vamos ter que arcar com o retrabalho. 


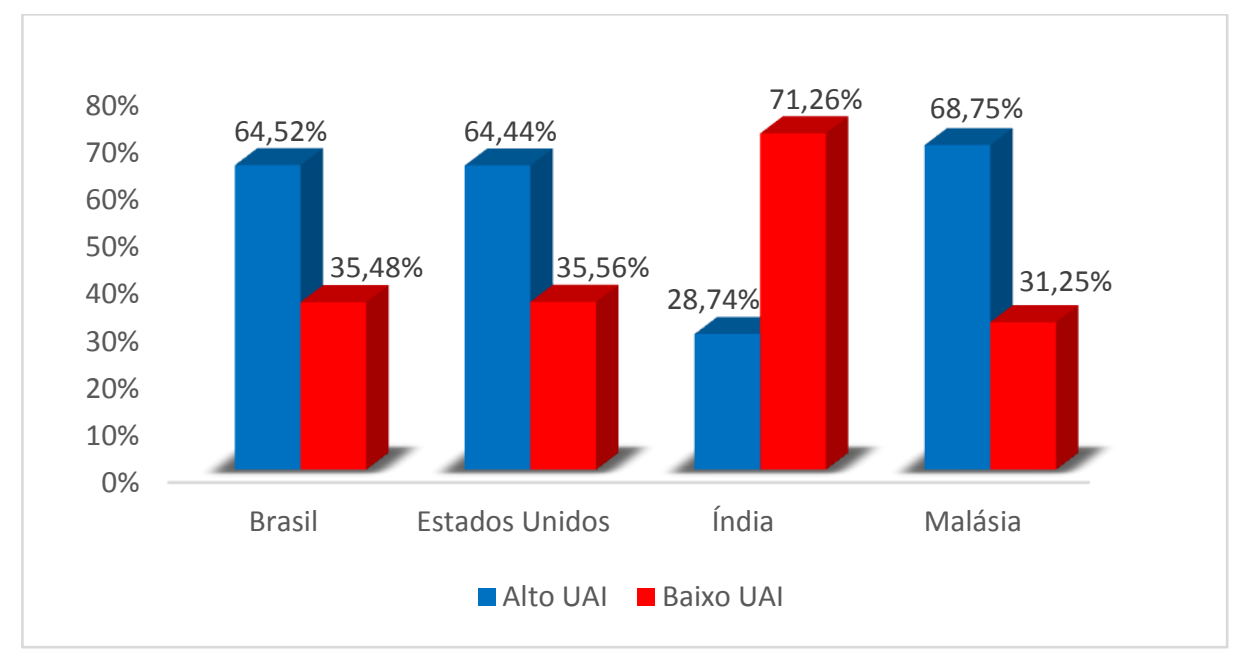

Figura 2: Resultados da dimensão aversão à incerteza

Fonte: Dados da pesquisa (2017)

De acordo com a Figura 2 (dois), em relação à dimensão aversão à incerteza, Brasil, Estados Unidos e Malásia apresentam altos índices (64,52\%, 64,44\% e 68,75\%, respectivamente). Em contrapartida, os indianos demonstram maior propensão à baixa aversão à incerteza $(71,26 \%)$.

\subsection{Dimensão 3: Individualismo versus Coletivismo}

Os dados demonstram que os americanos são mais individualistas enquanto os brasileiros, indianos e malaios são mais coletivistas. Conforme os estudos de Hofested (2001), a prevalência do coletivismo sugere um maior direcionamento para realizar trabalhos em equipe e, por outro lado, o individualismo indica uma busca maior por objetivos pessoais e preferência por trabalhar de forma independente.

A fala de um dos americanos ilustra o individualismo da cultura: "Nos passam uma tarefa e temos que gerenciá-la de maneira autônoma enquanto vamos fazendo outras atividades. Então, em uma base diária, você tem que fazê-la da sua própria maneira.".

Já a fala de um dos malaios ilustra a perspectiva mais coletivista: "Aqui na Malásia é mais comum ter decisões em grupo do que individuais. Sempre que é possível, nós procuramos o grupo para nos apoiar nas dificuldades.". Nesse mesmo sentido, um dos indianos aponta a sua nação e a brasileira como coletivistas: "Nesse aspecto, eu acho que Brasil e Índia são parecidos, pois somos focados em soluções diferentes. Opiniões divergentes sempre serão bem aceitas". 


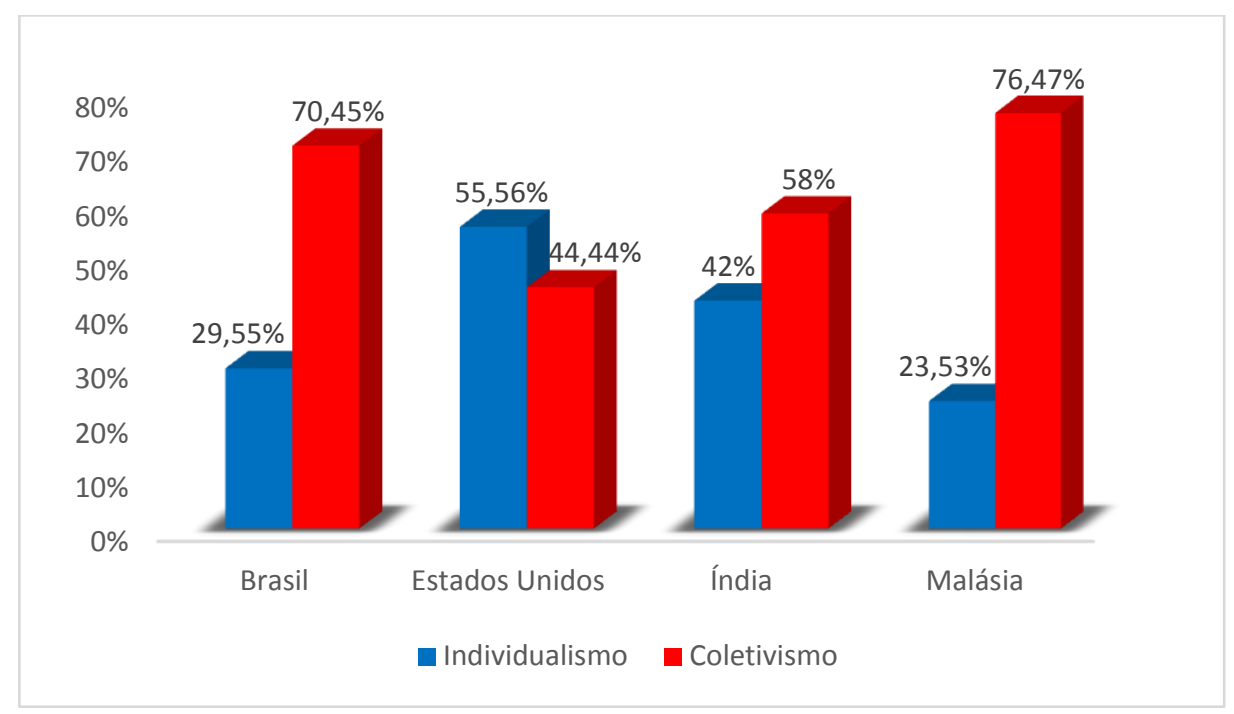

Figura 3: Resultados da dimensão individualismo versus coletivismo Fonte: Dados da pesquisa (2017)

A Figura 3 (três) expõe os resultados sobre a dimensão individualismo versus coletivismo. Conforme os dados da pesquisa, brasileiros, indianos e malaios possuem maior aproximação com um ambiente de coletividade, afirmação expressada nos percentuais: 70,45\%, 58\% e 76,47\%. Em contraste, o senso de individualidade foi maior representado pelos estadunidenses, apresentando um percentual de 55,56\%.

\subsection{Dimensão 4: Masculinidade versus Feminilidade}

Os traços de masculinidade são vistos de forma mais evidente entre os americanos enquanto as demais nacionalidades demonstram uma alternância entre padrões de masculinidade e feminilidade. Para Hofested (2001), a masculinidade está associada a buscar por conquistas, resultados, sucesso e ao heroísmo, enquanto a feminilidade está associada a características de humildade, busca por cooperação e preocupação com os demais.

A fala de um dos americanos ilustra características de masculinidade dessa cultura: "Eu diria que os americanos não veem problema de fazer 80 horas por semana se for necessário.”. Dessa mesma forma, um dos malaios registrou: "Indianos são bastante comprometidos com o trabalho e isso é muito emblemático para nós. Isso acaba até gerando certo nível de competitividade entre a nossa cultura e a deles.”.

Por outro lado, a fala de um dos brasileiros denota o caráter de feminilidade: "Muitas vezes, a gente não tem as soluções porque não conseguimos pensar em tudo e muito menos solucionar tudo, mas a gente consegue conversar com um colega. Dessa 
maneira, a gente consegue expor problemas e conseguir sugestões.”. Finalizando, um dos malaios relatou o seguinte: "Durante projetos, as negociações acontecem de duas maneiras indiretas e diretas. O que eu vejo acontecer é uma busca por situações ganhaganha, ou seja, eu ajudo você e você me ajuda [...]."

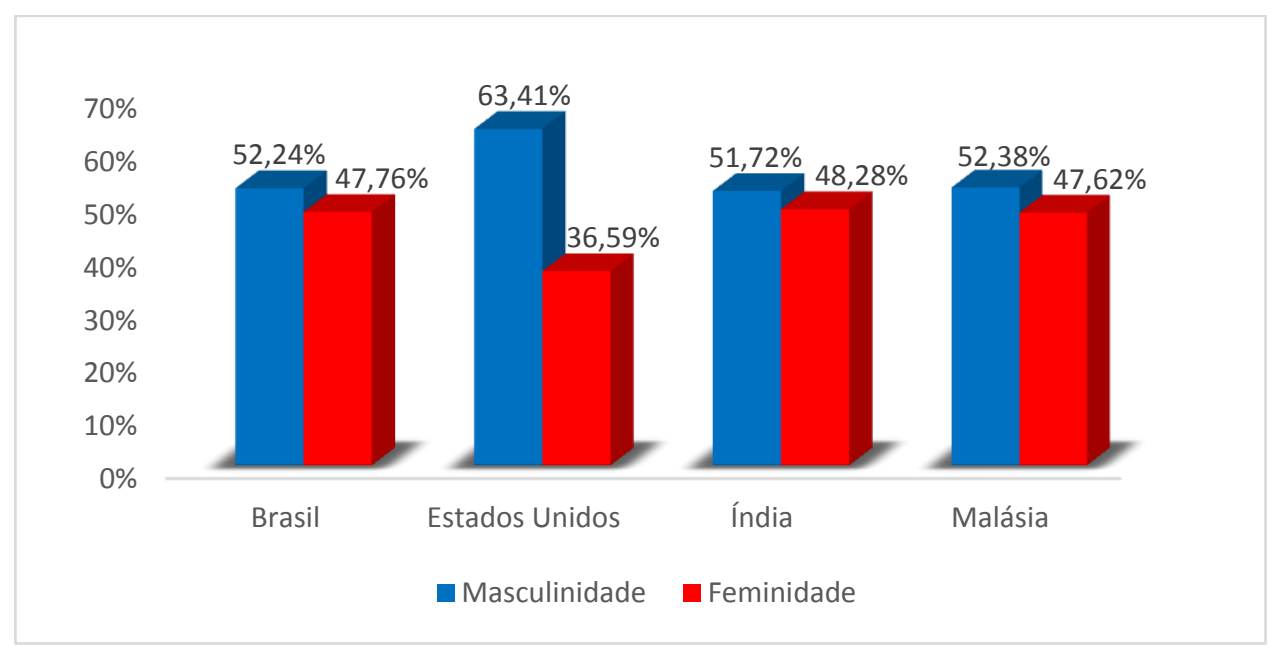

Figura 4: Resultados da dimensão masculinidade versus feminilidade Fonte: Dados da pesquisa (2017)

Referente à Figura 4, que corresponde aos resultados da dimensão masculinidade versus feminilidade, percebe-se que os estadunidenses apresentam o maior índice de masculinidade $(63,41 \%)$, apesar de um aparente equilíbrio entre as demais nacionalidades. Mesmo preponderante a masculinidade em todos os casos participantes, as nacionalidades com maior senso de feminilidade foram Brasil, Índia e Malásia, representando, na ordem de citação, 47,76\%, 48,28\% e 47,62\%.

\section{Considerações Finais}

A análise das dimensões que evidenciam as semelhanças e diferenças de culturas nacionais, conforme proposto por Hofested (2001), demonstra a diversidade cultural (COX, 1994) com a qual se deparam os líderes globais. Este estudo, especificamente, permitiu identificar as diferenças entre as culturas nacionais de americanos, brasileiros, indianos e malaios, atuantes em uma equipe de desenvolvimento de software.

O índice de distância do poder demonstra a necessidade do líder alternar uma postura mais centralizadora em relação a determinados indivíduos e mais democrática em relação a outros. A dimensão de aversão à incerteza evidencia que alguns grupos precisarão de mais informações na realização das tarefas para certificarem-se que estão 
fazendo corretamente as suas atividades (americanos, brasileiros e malaios). Por outro lado, os indianos, por sua maior tolerância à ambiguidade, poderão fazer as tarefas sem ter todas as informações necessárias e, com isso, incorrer a erros, o que exige do líder uma maior atenção.

Em relação a traços de individualidade e coletivismo, os americanos parecem precisar de maior independência por parte dos líderes, enquanto as demais nacionalidades demonstram precisar de maior integração grupal, porém um líder hábil também deve saber gerenciar e demonstrar que ambas as abordagens possuem pontos positivos e negativos. Quanto a aspectos de masculinidade e feminilidade, o comportamento mais agressivo, competitivo e voltado para resultados dos americanos será contrastado com a atitude mais cooperativa das demais nacionalidades.

A identificação das diferenças culturais permite que os líderes realizem a sua gestão de acordo com as peculiaridades e necessidades de cada grupo cultural e, dessa forma, possam obter o maior benefício conforme a situação de trabalho exigir (COX, 1994; MENDENHALL, 2013). Por exemplo, diante de indivíduos mais independentes, caso dos americanos, precisará dar maior autonomia. Por outro lado, deverá fornecer maiores informações e estar mais próximo dos indianos.

Os resultados da pesquisa também corroboram os achados da literatura científica acerca das competências necessárias para o líder global. São elas: mente aberta, adaptabilidade, sensibilidade global, conhecimento acerca de diferentes culturas (HASSANZADE, SILONG, ASMUNI e WAHAT, 2015), empatia e aceitação da complexidade e suas contradições (JOKINEN, 2005), comunicação intercultural (MENDENHALL, 2013) e abertura (CALIGIURI, 2006).

Este tipo de mapeamento também proporciona dados para as equipes de treinamento e desenvolvimento da área de recursos humanos, por servir como base para a elaboração de programas de desenvolvimento de lideranças globais compatíveis com a realidade organizacional e suas especificidades (JOKINEN, 2005). Afinal, a realização de um treinamento intercultural (CALIGIURI, 2006) deve estar contextualizada com as diferentes nacionalidades que compõem o quadro global da empresa.

A principal limitação deste estudo é o fato deste ter sido realizado em uma única empresa, de segmento específico e, por isso, os seus resultados não poderem ser generalizáveis. Sugere-se para estudos futuros: a inclusão de maior número de nacionalidades para ampliar a apreciação das diferenças e semelhanças culturais; incluir 
empresas de diferentes ramos para realizar comparações; fazer o estudo com enfoque quantitativo; e acrescentar a esta análise um índice que permita medir os impactos das diferenças culturais e a gestão destas nos resultados finais das empresas.

\section{Referência}

AGUZZOLI, R.. L.; LENGLER, J. F. B.; MANFREDINI, V. O estágio de internacionalização e sua influência sobre a gestão de pessoas. Anais do XXXI ENANPAD, Rio de Janeiro: ANPAD, 2007.

ALVARENGA, F. Z. Os efeitos da cultura nacional no desenvolvimento de sistemas de informação em equipes globalmente distribuídas. Porto Alegre: PUCRS, 2015. Dissertação (Mestrado em Administração e Negócios) Faculdade de Administração, Contabilidade e Economia, Pontifícia Universidade Católica do Rio Grande do Sul, 2015.

AMAGOH, F. Leadership development and leadership effectiveness. Management Decision, v. 47, n.6, p. 989-999, 2009.

BARDIN, L. Análise de conteúdo. Lisboa: Editora Edições 70, 2011.

BASS, B.; BASS, R. Concepts of Leadership. In: BASS, Bernard M; BASS, Ruth. The Bass Handbook of Leadership: Theory, Research \& Managerial Applications. 4th ed. New York: Free Press, 2008.

BLACK, J.S.; MENDENHALL, M.; ODDOU, G. Toward a Comprehensive Model of International Adjustment: An Integration of Multiple Theoretical Perspectives. Academy of Management Review, v.16, n.2, p.291-317, 1991.

CALIGIURI, P. Developing Global Leaders. Human Resource Management Review, v.16, p. 219-228, 2006.

CALIGIURI, P.; TARIQUE, I. Predicting effectiveness in global leadership activities. Journal of World Business, v.44, p. 336-346, 2009.

COX, T. Cultural diversity in organizations: theory, research and practice. San Francisco: Berrett-Koehler Publishers, 1994.

DONATO, R. A. Cultura nacional e o desenvolvimento de software em times globalmente distribuídos. Porto Alegre: PUCRS, 2013. Dissertação (Mestrado em Administração e Negócios) Faculdade de Administração, Contabilidade e Economia, Pontifícia Universidade Católica do Rio Grande do Sul, 2013.

DUTRA, J. S. Competências. São Paulo: Atlas, 2004.

FLEURY, M. T. L. Gerenciando a diversidade cultural: experiências de empresas Brasileiras. Rev. adm. empresas, v. 40, n. 3, p. 18-25, 2000. 
GIL, A. C. Métodos e Técnicas de Pesquisa Social. 6ª edição. São Paulo: Atlas, 2010.

HOFSTEDE, G. Culture's Consequences: Comparing Values, Behaviors, Institutions and Organizations Across Nations. 2 ${ }^{\mathrm{a}}$ Ed. Thousand Oaks, CA: Sage, 2001.

HASSANZADEH, M.; SILONG, A. D.; ASMUNI, A.; WAHAT, N. W. A. Global leadership competencies. Journal of Educational and Social Research, v.5, n.2, 2015.

JOKINEN, T. Global leadership competencies: a review and discussion. Journal of European Industrial Training, v. 29, n. 3, p. 199-216, 2005.

LESKIW, S.; SINGH, P. Leadership development: learning from best practices. Leadership \& Organization Development Journal, v. 28, n. 5, p. 444-464, 2007.

LINEHAN, M.; SCULLION, H. Repatriation of European female corporate executives: an empirical study International Journal of Human Resource Management. Vol. 13, n. 2, march, p. 254-267, 2002.

MENDENHALL, M. E. Leadership and the birth of global leadership. In: MENDENHALL, M. E; OSLAND, J.S; BIRD, A.; ODDOU, G. R.; MAZNEVSKI, M. L.; STEVENS, J. S.; STAHL, G. K. Global Leadership: research, practice, and development. 2 ed. London: Routledge, 2013.

RUAS, R. Gestão por competências: uma contribuição à estratégia das organizações. In: Aprendizagem e competências organizacionais. Porto Alegre: Bookmann, 2005.

SCHEIN, E. The corporate survival guide. San Francisco: Jossey-Bass, 2009.

SCULLION, H. Staffing policies and strategic control in British multinationals. International Studies of Management and Organization, vol. 4, n. 3, p. 18-35, 1994.

STEVENS, M. J.; ODDOU, G.; FURUYA, N.; BIRD, A.; MENDENHALL, M. HR factorsaffecting repatriate job satisfaction and job attachment for Japanese managers. International Journal of Human Resource Management. Vol. 17, n. 5, may, p. 831-841, 2006.

YIN, R. K. Estudo de Caso: Planejamento e métodos. Petrópolis: Bookman, 2010.

ZARIFIAN, P. Objetivo Competência: por uma nova lógica. São Paulo: Atlas, 2001. 